\title{
Increased recall rate at screening for congenital hypothyroidism in breast fed infants born to iodine overloaded mothers
}

\author{
J P CHANOINE, ${ }^{*} \ddagger$ M BOULVAIN,$\dagger$ P BOURDOUX,$\ddagger$ A PARDOU,${ }^{*}$ H V VAN THI, $\ddagger$ \\ A M ERMANS, $\ddagger$ AND F DELANGE* $\ddagger$
}

Departments of ${ }^{*}$ Paediatrics, †Obstetrics, and $\ddagger$ Radioisotopes, Saint-Pierre and Erasme Hospitals, Free University of Brussels, Belgium

SUMmARY Skin disinfection with povidine-iodine (PVP-I) is widely used in obstetrics. We evaluated the influence of PVP-I in mothers at delivery on the serum thyroid stimulating hormone concentrations of their infants at the time of screening for congenital hypothyroidism. The study covered 4745 infants who were either breast fed $(3659,77 \%)$ or bottle fed $(1086,23 \%)$; $3086(65 \%)$ of them were born to mothers with no iodine overload (controls) and $1659(35 \%)$ to mothers with iodine overload. Compared with the control group, the breast and bottle fed infants born to mothers with iodide overload had a shift of neonatal thyroid stimulating hormone concentration towards high values. The shift was maximal in the breast fed infants with a 25 to 30 fold increase in the recall rate at screening for congenital hypothyroidism (serum thyroid stimulating hormone $>50 \mathrm{mU} / \mathrm{l}$ ) while in the bottle fed infants, the recall rate was barely modified. In conclusion, the use of PVP-I in mothers at delivery induces a transient impairment of thyroid function in their infants, especially if breast fed. This situation is detrimental to screening for congenital hypothyroidism. Consequently PVP-I is not recommended in obstetrics.

Skin disinfection with povidone-iodine (PVP-I) is widely used in obstetrics in epidural anaesthesia or caesarean section. This procedure results in iodide overload of the mother due to cutaneous absorption of iodine. ${ }^{1}$ Iodide readily crosses the placenta ${ }^{2}$ and is actively concentrated in the mammary gland. ${ }^{3}$ Consequently, newborn infants born to mothers treated with PVP-I are also exposed to iodine overload, especially if breast fed. ${ }^{4}$

The thyroid gland of newborns is highly sensitive to the blocking effect of excess iodide on thyroid hormone synthesis, and a raised concentration of serum thyroid stimulating hormone is the most reliable index of impairment of thyroid function. ${ }^{5}$ The objective of the present work was to evaluate the influence of cutaneous application of PVP-I in mothers at delivery on the concentrations of thyroid stimulating hormone in their infants at the time of screening for congenital hypothyroidism. In order to appreciate the specific role of the iodine contained in breast milk, a comparative study was performed between breast and bottle fed infants.

\section{Patients and methods}

The study included 4745 (96\%) of the 4923 infants born in our maternity ward during a two year period. Of the 178 infants who were not included in the study, three were omitted because they had permanent congenital hypothyroidism due to thyroid agenesis with an appreciably raised serum thyroid stimulating hormone concentration and a low thyroxine concentration at screening and diagnosis. One hundred and seventy five (45 full term and 130 premature infants) were omitted because they were neither breast nor bottle fed: they were severely ill and received total parenteral nutrition until at least the fifth day of life. None of these 175 infants had a serum thyroid stimulating hormone concentration $>50 \mathrm{mU} / \mathrm{l}$ at the time of screening for congenital hypothyroidism.

The 4745 infants under study were investigated on the fifth day of life at the time of screening for congenital hypothyroidism. As shown in table 1 they were distributed in several groups on the basis of the 
Table 1 Definition of the groups of newborn infants under investigation

\begin{tabular}{lccc}
\hline & Breast fed & Bottle fed & Total (\%) \\
\hline No iodine overload & 2358 & 728 & $3086(65)$ \\
Epidural anaesthesia & 980 & 283 & $1263(27)$ \\
Caesarean section & 321 & 75 & $396(8)$ \\
Total (\%) & $3659(77)$ & $1086(23)$ & $4745(100)$ \\
\hline
\end{tabular}

type of feeding and the absence or presence of iodine overload: $3659(77 \%)$ of the infants were breast fed and $1086(23 \%)$ were bottle fed; 3086 $(65 \%)$ were born to mothers with no iodine overload, $1659(35 \%)$ were born to mothers with iodine overload due to the cutaneous application of PVP-I at delivery for epidural anaesthesia or caesarean section. In the former, a cutaneous surface of about $900 \mathrm{~cm}^{2}$ was covered by one single application of PVP-I. In the latter, the whole abdominal wall was covered by three applications of PVP-I. The $10 \%$ solution of PVP-I used contained $10 \mathrm{mg}$ of iodine $/ \mathrm{ml}$.

All the newborn infants were submitted to systematic neonatal screening for congenital hypothyroidism; serum thyroid stimulating hormone concentration was used as the primary screening test. When thyroid stimulating hormone concentration was above $20 \mathrm{mU} / \mathrm{l}$ serum thyroxine was measured in a second step from the initial blood spot. The criteria used for recalling an infant under suspicion of congenital hypothyroidism were a serum thyroid stimulating hormone concentration of $>50 \mathrm{mU} / \mathrm{l}$ or a thyroid stimulating hormone concentration between 20 and $50 \mathrm{mU} / \mathrm{l}$ associated with a serum thyroxine concentration of $<64 \mathrm{nmol} / \mathrm{l} .^{6}$ Further investigation included clinical, biological, and radiological assessments, and when necessary the infants were scanned. Serum thyroid stimulating hormone and thyroxine were measured in duplicate by specific radioimmunoassay: at screening on blood spots dried on filter paper (the sensitivity was $40 \mathrm{mU} / \mathrm{l}$ for thyroid stimulating hormone and $13 \mathrm{nmol} / \mathrm{l}$ for thyroxine) and at recall on serum (the sensitivity was $0.4 \mathrm{mU} / \mathrm{l}$ for thyroid stimulating hormone and $13 \mathrm{nmol} / \mathrm{l}$ for thyroxine). ${ }^{7}$

Statistical analyses determined the frequency distribution of serum thyroid stimulating hormone concentrations in the whole infant population under study and compared this distribution in the different groups. The frequency distributions were compared by $\chi^{2}$ tests.

\section{Results}

The frequency distribution of serum thyroid stimulating hormone concentration in the 4745 infants studied is shown in fig 1 . The distribution was asymmetrical and skewed towards low values: 4311 $(91 \%)$ of the values were $<10 \mathrm{mU} / \mathrm{l}, 388(8 \%)$ were moderately raised between 10 and $50 \mathrm{mU} / \mathrm{l}$, and as many as $46(1 \%)$ of the infants had a serum thyroid stimulating hormone $>50 \mathrm{mU} / \mathrm{l}$ and were thus recalled. None was recalled on a basis of a thyroid stimulating hormone concentration between 20 and $50 \mathrm{mU} / \mathrm{l}$ associated with a thyroxine concentration $<64 \mathrm{nmol} / \mathrm{l}$.

The frequency distributions of serum thyroid stimulating hormone concentrations in the different groups of infants considered are shown in fig 2: in the breast fed infants born to mothers treated with PVP-I, there was a clear cut shift of serum thyroid stimulating hormone towards high values.

The recall rate increased from $0.1 \%$ in the absence of iodine overload to $3 \cdot 2 \%$ in case of epidural anaesthesia and $2.7 \%$ in case of caesarean section. Serum thyroxine concentration at screening and at the time of recall for control examinations was normal in all infants. In the bottle fed infants, there was also a slight shift towards raised thyroid

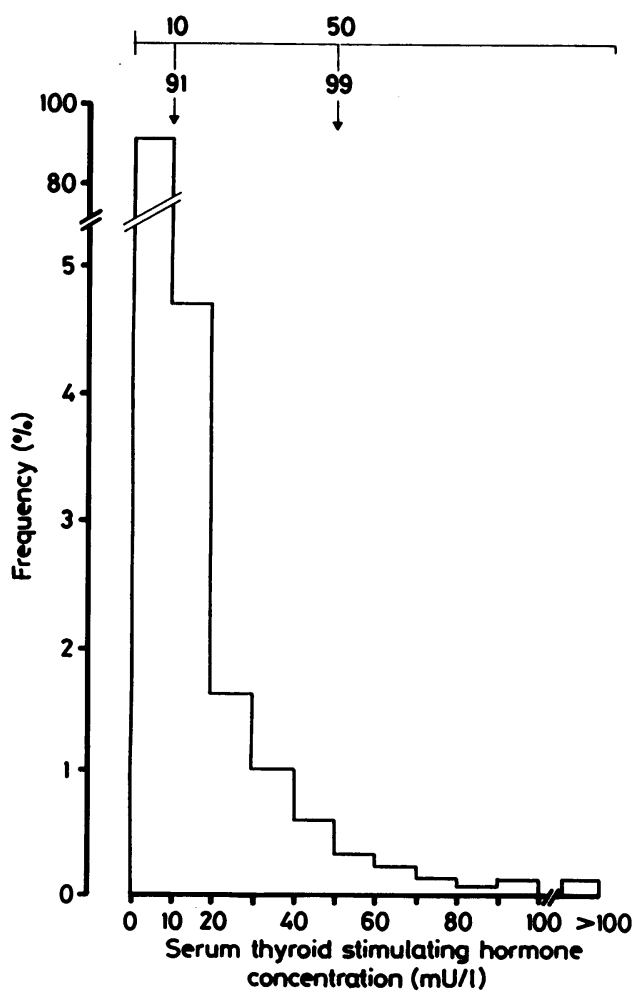

Fig 1 Frequency distribution of the serum thyroid stimulating hormone concentration $(\mathrm{mU} / \mathrm{l})$ on day five in all newborn infants under investigation $(n=4745)$. 
Breastfed infants $(n=3659)$

Bottlefed infants $(n=1086)$

No iodine overload
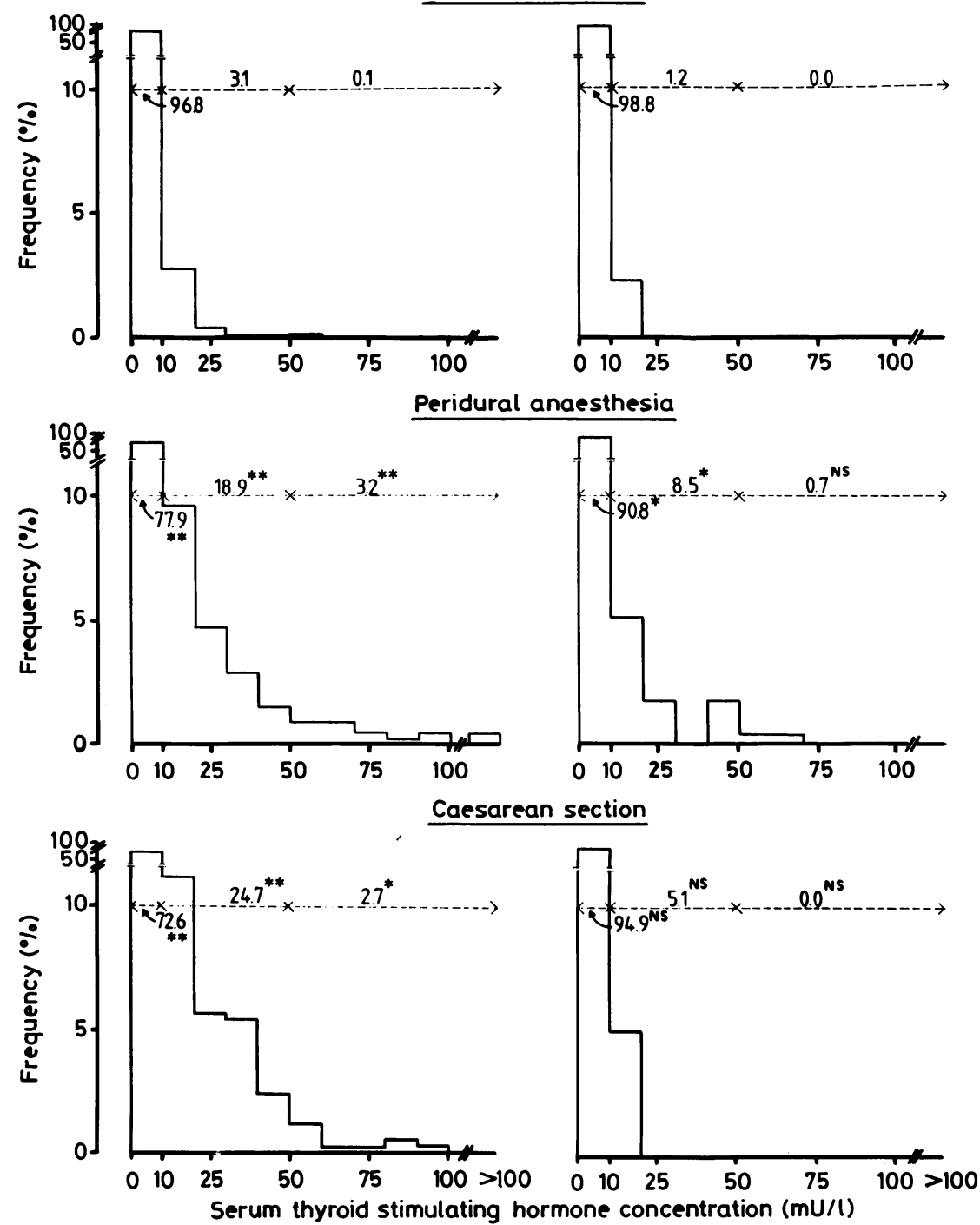

Fig 2 Comparison of the frequency distributions of the serum thyroid stimulating hormone concentration (mU/l) on day five in the different groups of newborn infants considered. The numbers on the dotted lines represent the cumulated frequencies of the serum thyroid stimulating hormone concentrations included in the arrows. The levels of significance both in breast and bottle fed infants refer to the comparison with the group with no iodine overload; ${ }^{*}=p<0.05 ;{ }^{* *}=p<0.01$.

stimulating hormone concentrations in the iodine contaminated groups. The shift was much less pronounced, however, than in breast fed infants and the recall rate was barely modified.

\section{Discussion}

The present work shows that one cutaneous applica- tion of PVP-I in mothers at the time of delivery results in a shift of neonatal thyroid stimulating hormone towards raised concentrations both in breast fed and bottle fed infants. The shift is much more important in the case of breast feeding, where there is a 25 to 30 fold increase in the recall rate.

The cause of the shift in breast fed infants is 
obviously iodine overload. We have previously reported that there was a two and 12 fold increase in the iodine content of breast milk after the use of PVP-I for epidural anaesthesia and caesarean section respectively (table 2 ). ${ }^{4}$ The shift in bottle fed infants probably results from moderate fetal iodine overload occurring between skin disinfection with PVP-I and delivery because of a transfer of iodine across the placenta.

Chabrolle and Rossier have shown that the application of PVP-I directly on the skin of infants occasionally increases their serum thyroid stimulating hormone concentrations. ${ }^{8}$ Our results indicate that the same phenomenon occurs when PVP-I is used in the mother before delivery.

In our study, all infants with moderately or appreciably raised serum thyroid stimulating hormone concentrations at screening had normal thyroxine at screening and all further investigations were also normal. Consequently, the raised serum thyroid stimulating hormone indicates a very transient state of compensated or subclinical hypothyroidism which, most probably, will not affect the long term development of the infants. ${ }^{59}$ Our study, however, underlines the public health importance of these transient alterations. In the newborn population under study, the recall rate was $1 \%$ instead of $0.2 \%$ in our screening programme. ${ }^{10}$ In addition, there was a clear cut increase in the frequency of moderately raised thyroid stimulating hormone between 10 and $50 \mathrm{mU} / \mathrm{l}$, which also indicates some impairment of thyroid function, although the infants were not recalled.

This high recall rate is detrimental to the screening programme and increases its cost because of the further investigations needed. It also appreciably increases the frequency of so called 'false positives' at screening; this is an unfavourable situation for a screening programme. ${ }^{11}$ Finally, but of major importance, the high recall rate causes unnecessary psychological stress in many families. Long term effects of this recall on the mother-infant relationship have been well documented; these adverse effects

Table 2 Iodine content of maternal milk at the fifth postnatal day with and without iodine overload. (Modified from Chanoine et $\mathrm{al}^{4}$ )

\begin{tabular}{ll}
\hline & $\begin{array}{l}\text { Mean }(S D) \text { iodine concentration } \\
(\mu \text { molll })\end{array}$ \\
\hline $\begin{array}{l}\text { No iodine overload } \\
\text { Iodine overload after: } \\
\text { Epidural anaesthesia }\end{array}$ & $0.75(0 \cdot 05)$ \\
$\quad \begin{array}{l}1.26(0.11) \\
\text { Caesarean section }\end{array}$ & $9.98(3.31)$ \\
\hline
\end{tabular}

were present even when the results of the control examinations were normal. ${ }^{12}$

In conclusion, the use of PVP-I in mothers at delivery can result in a mild Wolff-Chaikoff effect in the infant, especially if breast fed. Impairment of thyroid function is transient and probably without major consequences. It unnecessarily increases the recall rate, however, and consequently the cost of the screening and stress on families. Therefore PVP-I is not recommended in obstetrics.

Work supported in part by a grant of the Fonds de la Recherche Scientifique Médicale (FRSM, Belgium, contract n. 3.4507.81) and by the Fondation David et Alice Van Buuren. We thank Dr Haumont (Department of Paediatrics, Saint-Pierre Hospital) and Dr Schwerz (Department of Obstetrics, Erasme Hospital) for their help and support.

See letter from Chanoine et al in Correspondence column p. 1297.

\section{References}

1 Glöbel B, Glöbel H, Andres C. Resorption von Jod aus PVPJod-Präparaten nach Anwendung am Menschen. Dtsch Med Wochenschr 1984;109:1401-4.

2 Roti E, Gnudi A, Braverman LE. The placental transport, synthesis and metabolism of hormones and drugs which affect thyroid function. Endocr Rev 1983;4:131-49.

${ }^{3}$ Brown-Grant $K$. The iodide concentrating mechanism of the mammary gland. $J$ Physiol 1957;135:644-54.

${ }^{4}$ Chanoine JP, Bourdoux P, Pardou A, Delange F. Iodinated skin disinfectants in mothers at delivery and impairment of thyroid function in their breastfed infants. In: Medeiros-Neto GA, Gaitan E, eds. Frontiers of thyroidology. New York: Plenum Press, 1986:1055-60.

${ }^{5}$ Delange F, Bourdoux P, Ermans AM. Transient disorders of thyroid function and regulation in preterm infants. In: Delange F, Fisher D, Malvaux P, eds. Pediatric thyroidology. Basel: Karger, 1985:369-93.

${ }^{6}$ Delange F, Bourguignon JP, Bourdoux P, Ermans AM. Le dépistage de l'hypothyroidie congénitale. Aspects diagnostiques et thérapeutiques. Rev Méd Liège 1984;39:437-47.

7 Bourdoux P, Putzeys G, Lagasse R, Van Steirteghem A. Biochemical and statistical methods. In: Delange F, Iteke FB, Ermans AM, eds. Nutritional factors involved in the goitrogenic action of cassava. Ottawa: International Development Research Centre, 1982;20-4.

${ }^{8}$ Chabrolle JP, Rossier A. Goitre and hypothyroidism in the newborn after cutaneous absorption of iodine. Arch Dis Child 1978;53:495-8.

${ }^{9}$ Grüters A, L'Allemand D, Heidemann PH, Schürnbrand P. Incidence of iodine contamination in neonatal transient hyperthyrotropinemia. Eur J Pediatr 1983;140:299-300.

10 Delange F, Heidemann P, Bourdoux P, et al. Regional variations of iodine nutrition and thyroid function during the neonatal period in Europe. Biol Neonate 1986;49:322-30.

1 Laberge C. Organization and cost benefit of mass screening programs. In: Burrow GN, Dussault JH, eds. Neonatal thyroid screening. New York: Raven Press, 1980:189-98.

12 Fyrö K, Bodegard G. Four-year follow-up of psychological reactions to false positive screening tests for congenital hypothyroidism. Paediatr Scand 1987;76:107-14.

Correspondence and requests for reprints to Dr JP Chanoine, Department of Radioisotopes, Hospital Saint-Pierre, Rue Haute, 322, B 1000 Brussels, Belgium.

Accepted 12 February 1988 